government will have to make it clear that it intends to require NHS hospital trusts and private hospitals to provide data within the hospital episode system ${ }^{9}$ because these are required to generate denominators for the epidemiological surveys that regions are being required to set up. Regional epidemiological surveys are seen by the government to be not only invaluable for surveillance and a guide to where action is needed but also an essential precursor to introducing multidisciplinary confidential inquiry into particular categories of stillbirths and infant deaths. A working group is being set up by the chief medical officer to consider what form this might take.

In any inquiry process some categories of death - such as haemolytic disease, trauma, or respiratory distress in babies. weighing more than $1000 \mathrm{~g}$-might be studied as uncontrolled case series to assess whether care known to reduce the risk of death from these causes had been provided. Other categories - such as unexpected antepartum deaths of normally formed fetuses - would be more profitably investigated in case-control studies until more is understood about the underlying pathological processes and the means of successfully interrupting them. ${ }^{10}$ Those collaborating in the Northern region have already embarked on several such studies, and this would be a sensible place to pilot plans for any national confidential inquiry while other regions establish comparable surveys to ensure valid interregional comparisons and cross regional sampling of particular categories of death.

The government concludes the summary of its response to the Social Services Committee's report by expressing its belief that its initiatives will help to ensure that infant mortality becomes as low as possible. It does not refer to the possibility that striving for the highest possible rates of survival, while securing normal lives for many children who might otherwise have died, may also have tragic consequences for some other children. The rate of cerebral palsy among children who were born weighing less than $2500 \mathrm{~g}$ has risen in all of the populations for which data are available, ${ }^{11-14}$ and the overall rate of cerebral palsy in Sweden is now higher than at any time since records began. The government must accept that these and other children should be seen as the casualties of policies designed to ensure that infant mortality becomes as low as possible. It has an immediate duty to ensure that these children and their families receive the support they require to help them cope with the consequences of their disabilities. It has a further duty to ensure that the necessary data are available to monitor trends in cerebral palsy and other forms of impairment and to support the research required to identify ways of reducing the risk not only of infant death but also of serious impairment in children.

National Perinatal Epidemiology Unit, IAIN CHALMERS Director

Radcliffe Infirmary, Oxford OX2 6HE

1 Department of Health. Perinatal, neonatal and infant mortality: government reply to the first report of the Social Services Committee, session 1988-89. London: HMSO, 1989. (Cmnd 741.)

2 Chalmers I, Mcllwaine G, eds. Perinatal audit and surveillance. London: Royal College of Obstetricians and Gynaecologists, 1980.

3 Chalmers I. Enquiry into perinatal death. Br f Obstet Gynaecol 1985;92:545-9.

4 Barron SL. How can we improve perinatal surveillance? Br f Obstet Gynaecol 1986;93:1201-3.

5 Northern Regional Health Authority Coordinating Group. Perinatal mortality: a continuin collaborative regional survey. Br Med f 1984;288:1717-20.

6 Cole SK, Hey EN, Thomson AM. Classifying perinatal death: an obstetric approach. Br 7 Obstet Gynaecol 1986;93:1204-12.

7 Hey EN, Lloyd DJ, Wigglesworth JS. Classifying perinatal death: fetal and neonatal factors. Brf Obstet Gynaecol 1986;93:1213-23.

8 Macfarlane $\mathrm{A}$, Cole $\mathrm{S}$, Hey E. Comparisons of data from regional perinatal mortality surveys. Brf Obstet Gynaecol 1986;93:1224-32.

9 Freeman R. Parliamentary written answer. House of Commons Official Report (Hansard) 1989 March 6;148:col 415. (No 63.)

10 Chalmers I. Enquiry into perinatal death: a report on national perinatal surveillance prepared for the Department of Health and Social Security. Oxford: National Perinatal Epidemiology Unit, 1984.

11 Hagberg B, Hagberg G, Olow I, von Wendt L. The changing panorama of cerebral palsy in Sweden. V. The birth year period 1979-82. Acta Paediatr Scand 1989;78:283-90.

12 Dowding V, Barry C. Cerebral palsy: changing patterns of birthweight and gestational age 1976/81). Ir Med f 1988;81:25-9.

13 Pharaoh POD, Cooke T, Rosenbloom I, Cooke RWI. Trends in the birth prevalence of cerebral palsy. Arch Dis Child 1987;62:379-89.

14 Stanley FJ, Watson L. The cerebral palsies in Western Australia: trends, 1968 to 1981. Am $\mathcal{J}$ Obstet Gynecol 1988;158:89-93.

\title{
Radiology about to go digital
}

\section{Exciting new technology must be carefully evaluated}

Computed tomography, radionuclide scanning, digital subtraction angiography, and magnetic resonance imaging account for up to one third of examinations in modern radiology departments: they yield digital data, giving measurements of physical values from which images are constructed. At present these images are printed on film. The technology now exists to transform other examinations into digital procedures. Computed radiography is a Japanese innovation that replaces $x$ ray film with a reusable phosphor material. ${ }^{12}$ After exposure with conventional radiographic equipment the phosphor sheet is removed from its cassette and scanned to convert the stored image into digital data. The system is more sensitive than film, and more tolerant of incorrect exposure; the procedure entails less radiation and, theoretically, no chemicals and no film.

Linking imaging technology in a computerised network that would allow radiologists and doctors in clinics and operating theatres to deal exclusively with digital images on television systems has long been a pipe dream. ${ }^{3+}$ In the early days, however, few people fully appreciated the true scale of the undertaking. The London Stock Exchange now generates 350 megabytes of data from each day's trading; a fully digital radiology department in a typical hospital might easily produce 2 gigabytes - nearly six times more.

Single full sized optical disks are inadequate for storing such huge amounts of image data. Optical jukeboxes have been devised to handle 90 or more disks, and there is now the prospect of optical tape that might store a terabyte of data (1 million megabytes) on a single reel. In a hospital with a fully digital radiology system thousands of images from hundreds of patients would need to be instantly available for viewing in dozens of locations. This would give rise to enormous problems with data traffic. Laying down standards and finding ways for existing and future equipment-even from a single manufacturer - to communicate in the same language is difficult and costly. The many technical problems have been studied intensively, mostly in the United States. ${ }^{56}$ The work has been largely conducted by psychiatrists, computer scientists, and engineers.

As solutions appear for technical problems formidable pressure to implement the new technology becomes inevitable - rather like the pressure to introduce a wonder drug that is not yet available for clinical use. This is of special concern to hospitals that are rebuilding or planning for the future and have to consider the prospects for installing a complete network. They need to exercise caution and restraint. There is a sharp contrast between the missionary zeal of those who are frustrated with film but have had no practical experience with the new systems and the realism of established research teams. 
The digital systems will not be a panacea for every radiological ill, and no manufacturer has installed a total system anywhere. There is a strong case to be made against a department or hospital trying to "go digital" in a single move. Even today the text based computerisation of a hospital department, an operation of trivial proportions by comparison, may precipitate chaos. Few hospitals have yet done on a larger scale with text what we would like to do with images. Furthermore, the new equipment is undergoing rapid development: most hardware is obsolescent in about a year.

The most crucial issue is whether the diagnostic quality of the images will be impaired. The average casualty $x$ ray department carries out around 140 examinations of normal skulls for each radiograph that shows a fracture; there is no point in being able to store electronically, manipulate, and retrieve all those normal images unless we can be confident that they are truly normal and that the solitary abnormal case will not be missed. Clinical evaluation is now essential-it must include input by diagnostic radiologists and be independent and scientifically sound. Image quality should not be assessed subjectively; exacting scientific methods now permit accurate and reproducible study. ${ }^{7-9}$ It is greatly to the credit of the Department of Health that a British department is among the first to have produced an objective appraisal of displayed images from commercially available systems. ${ }^{1011}$ Such studies show that much refinement is still necessary.

Unless evaluation retains the priority it deserves there is a danger that implementation will be driven by the technology and by commercial considerations. An incremental, phased implementation of the new digital technology based on careful evaluation of each component is essential.

Honorary Senior Research Fellow,

RICHARD M DAWOOD

St Mary's Hospital Medical School,

London W2 INY

\footnotetext{
1 Tateno Y, linuma T, Takamo M. Computed radiography. Tokyo: Springer Verlag, 1987.

2 Kangarloo H, Boechat MI, Barbaric Z, et al. Two-year clinical experience with a computed radiography system. $A \mathcal{F} R$ 1988;151:605-8.

3 Craig JOMC. Diagnostic radiology without films. Practitioner 1985;299:1011-5.

4 Capp MP, Roehrig H, Seely GW, Fisher HD, Ovitt TW. The digital radiology department of the future. Radiol Clin North Am 1985;23:349-55.

Templeton AW, Cox GG, Dwyer SJ. Digital image measurement networks: current status. Radiology 1988;169: 193-9.

6 Huang HK. Elements of digital radiology: a professional handbook and guide. Englewood Cliffs, New Jersey: Prentice Hall, 1987.

Metz CE. Basic principles of ROC analysis. Semin Nucl Med 1978;8:283-98.

8 Metz CE. ROC methodology in radiologic imaging. Invest Radiol 1986;21:720-31.

$9 \mathrm{Metz}$ CE. Some practical issues of experimental design and data analysis in radiological ROC studies. Invest Radiol (in press).
s.

10 Dawood RM, Craig JOMC, Highman JH, et al. Clinical diagnosis from digital displays: preliminary findings of the St Mary's evaluation project. Clin Radiol (in press).

11 Dawood RM, Craig JOMC, Highman JH, et al. Evaluation of VDU displays in radiological diagnosis: a preliminary comparison of two systems. SPIE Proceedings 1989;1091:368-72.
}

\section{Rear seat belts}

\section{Should be encouraged by a mixture of legislation and incentives}

A law requiring car drivers and front seat passengers to use safety belts was introduced just over six years ago. It was an immediate success: the number of fatal and serious injuries to front seat occupants fell in the first 12 months, although only in those (who made up most of the travelling public) complying with the new legislation. ${ }^{12}$ Rates of seat belt use have remained extremely high in Britain ever since, and the associated reductions in death and injury continue.

In contrast, rear seat belts are worn infrequently, and there is a widespread public belief that it is "safer in the back" - that seating position is more important than using seat belts. Studies of the behaviour of dummies in controlled frontal impacts do not support this view: the rear seat occupants are catapulted into the front seats, damaging themselves and those in their path. Griffiths and his colleagues have estimated that deaths of front seat occupants might be reduced by a further $6 \%$ if this loading effect was eliminated by using rear seat belts and that three quarters of rear seat occupants who die would survive (paper to the 20th annual meeting of the United States Society of Automotive Engineers, 1976).

Wild and his colleagues, reporting a clinical study, could not confirm the loading hypothesis, possibly because their comparative groups were very dissimilar, reflecting the unpopularity of rear seat belts. ${ }^{3}$ Of 2520 car occupants, only two adults and 19 children were restrained rear seat passengers. Nevertheless, most of the injuries to those in rear seats were caused by changes in velocity rather than vehicle intrusion. They concluded that seat belts would be particularly valuable in preventing injuries caused by this type of accident.

Dreghorn, reviewing the effect of seat belt legislation on the work of a district general hospital, found that unbelted rear seat passengers had more numerous and more severe injuries than those who were restrained in the front seat and that they were twice as likely to require admission to hospital. ${ }^{4} \mathrm{~A}$ survey conducted in Leicester reported that the pattern of injuries was influenced more by the use of seat belts than by seating position. ${ }^{5}$

Rear belt anchor points have been required in all cars sold in the United Kingdom since 1982, and rear seat belts have been fitted to all new cars since 1987. The percentage of cars on the road with rear seat belts will increase rapidly over the next few years, and in 1993 a directive from the European Community will propose that all car occupants wear seat belts where these are fitted.

Some two fifths of those who occupy rear seats, however, are children (G M Mackay, personal communication), and providing effective restraints for them poses special problems because of their size and pelvic immaturity. Legislation will have to reflect the varying demands of the babe in arms and the young teenager. Nevertheless, recent surveys suggest that the public would welcome its introduction. In 1987 a Gallup poll conducted on behalf of the Parliamentary Advisory Council on Transport Safety reported that $92 \%$ of respondents favoured legislation requiring children to be secured in rear seats; the figure for adults was $70 \%$ (Jean Breen, personal communication). In a survey in New Zealand Langley et al found that only $2 \%$ of parents would oppose a law which required children of all ages to be restrained while travelling by car. ${ }^{6}$

This public support for compulsory rear seat restraint for children should ensure the success of the Motor Vehicles (wearing of rear seat belts by children) Act 1988, which will come into effect later this year. The need for the legislation is emphasised by a recent report from Cardiff which showed that only a quarter of children were always restrained correctly. ${ }^{7}$ The regulations for children over 4 years should be straightforward. With booster cushions and modifications to the lap anchor points, these children may use adult seat belts. The financial outlay is minimal, and the system may be 